\title{
An investigation on using pre-treated tyre rubber as a replacement of synthetic polymers for bitumen modification
}

\section{Ayad Subhy *_ Davide Lo Presti *__ Gordon Airey *}

* Nottingham Transportation Engineering Centre, University of Nottingham, Nottingham, UK

Ayad.Subhy@nottingham.ac.uk; ayad.s_eng@yahoo.com

\begin{abstract}
Rubberized bitumen obtained through a swelling process, has widely proven to be a successful technology for asphalt pavement applications and a solution to reduce the dismantling of tyre rubber on landfills. However, this technology presents two main operative issues which needs the adoption of costly special equipment. Firstly, significant high value of High Temperature Viscosity (HTV) which imposes mixing and compaction difficulties and leads to increased energy consumption and emissions. Furthermore, during the hot storage period, phase separation between rubber particles and the base bitumen could occur. Developing Recycled Tyre Rubber Modified Bitumen (RTR-MBs) with improved storage stability and reduced values of HTV could allow using this technology in standard asphalt plants, resulting in an environmental-friendly and cost-effective option of standard Polymer Modified Bitumen (PMBs). In this study, two different pre-treated and one straight ambient recycled rubbers were used to produce RTR-MBs. The first RTR was pre-treated by special oil and Warm Mix Additives (WMA) and the second was partly devulcanised. Also, two base binders were selected with large differences in mechanical properties in order to identify the effect of base binder. The high temperature viscosity was successfully reduced by using pre-treated RTR. The use of RTR together with FischerTropsch wax (Sasobit $\left.{ }^{\circledR}\right)$ in bitumen technology offered superior high in-service temperature properties and reduced value of HTV, and thus can be preferred option over styrene-butadiene-styrene (SBS) modification.
\end{abstract}

KEYWORDS: Recycled Tyre Rubber (RTR), devulcanised rubber, FT-wax, rutting resistance, rheological properties, High Temperature Viscosity HTV, modified bitumen

EATA 2015, pages 1 to 28 


\section{Introduction}

Incorporating RTR into flexible pavement applications by the means of wet process could solve a serious waste problem, save energy and materials, and enhance pavement life and performance. Many benefits are obtained by using RTR-MBs in road pavement applications; amongst them are improved temperature susceptibility, improved rutting and fatigue characteristics, lower maintenance/repair costs, durable pavements (longer life), improved resistance to oxidative ageing, reduced traffic noise, improved safety due to better skid resistance and darker colour due to carbon black in the rubber. However, the manufacture of RTR-MBs mixes requires higher temperatures due to their increased HTV which cause emission problems and further harden the asphalt (Glover et al. 2000). Also, the RTR-MBs cannot be stored for long periods after production because of the lack of compatibility between RTR and binder that leads to a phase separation problem. Many studies have been conducted to produce RTR-MBs that have reduced HTV and/or extended shelf life characteristics (Zanzotto and Kennepohl 1996, Billiter et al. 1997, Glover et al. 2000, Akisetty et al. 2009, Attia and Abdelrahman 2009, Akisetty et al. 2011, Rodríguez-Alloza et al. 2013). Some researchers utilized much severer curing conditions and fine rubber particles to overcome or alleviate these problems (Zanzotto and Kennepohl 1996, Billiter et al. 1997, Glover et al. 2000, Attia and Abdelrahman 2009). But, adopting high cure conditions could have negative impacts by further hardening the base binder and causes extra emission (Glover et al. 2000). Also, the polymer cross-link density would be reduced as severe temperature could cause breaking of the cross-linking network of polymer corresponded to a gradual reduction in the modification level (Abdelrahman 2006). Limited studies have considered applying warm-mix technology additives (WMA) to the RTR-MBs in order to lower the mixing and compaction temperatures and allow better workability and handling (Akisetty et al. 2009, Akisetty et al. 2011, Rodríguez-Alloza et al. 2013). On the other hand, fewer studies have considered using devulcanised rubber by the cleavage of cross-linking sulphur bonds in rubber vulcanizates without cleavage of the polymer chain bonds, this resulted in improving the dispersion and interfacial adhesion of RTR and binder (Dong et al., 2011; Liang, 1999; Liang \& Woodhams, 1998; Xiao-qing et al., 2009). Even though, utilizing devulcanized rubber as bitumen modifier showed enhanced properties and storage stability, there are very limited published studies in this area because of the high level of contaminated fumes and unpleasant odours associated with the processing procedure of in situ devulcanization (Dong, Li et al. 2011).

In this study, different new technologies of RTRs together with two base binders were used to produce RTR-MBs. The rheological properties of RTR-MBs were investigated within linear and nonlinear strain ranges and identify the RTR-MBs with desirable physical properties that can compete with the SBS modified bitumen. The first RTR technology was pre-treated with special oil and Fischer-Tropsch wax 
$\left(\right.$ Sasobit ${ }^{\circledR}$ ), and the second consisted of partly devulcanised RTR. A straight ambient RTR is also considered in this study to compare it with other new RTR technologies. The RTR-MBs were manufactured by utilising simple laboratory tools, Brookfield Viscometer with a modified impeller (Dual Helical Impeller DHI), see Figure 1. These tools allow to practical investigation many variables associated in manufacturing the RTR-MBs. The tools can also precisely control the temperature, continuously monitor the viscosity measurements in real-time, keep the rubber uniformly distributed within the blend by creating a convective like flow, and consume as little as 10-15 g of material (Celauro et al. 2012, Lo Presti et al. 2014, Lo Presti \& Airey 2013).

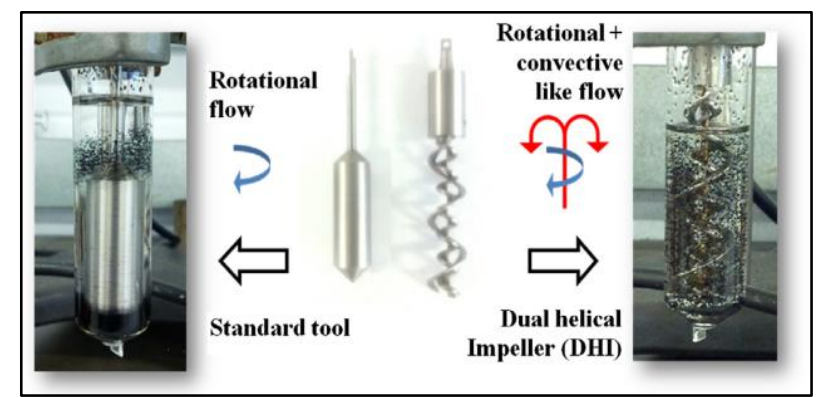

Figure 1. The modified Dual Helical Impeller (DHI) (Lo Presti et al. 2014)

\section{Materials and experimental program}

\subsection{Materials}

Two straight bituminous binders were used in this study, named " $H$ " and "S"; their properties are presented in Table 1. Obviously, the binder " $\mathrm{H}$ " is much harder than binder "S", and has asphaltenes content three folds higher than binder "S". Three different sources of RTRs were used, labelled as TRN, TRD and TRSE. TRN is a recycled rubber, derived from discarded truck and passenger car tyres by ambient grinding supplied by J. Allcock \& Sons Ltd (England). TRD is also recycled from truck and passenger car tyres by also ambient grinding but contains $20 \%$ devulcanised rubber supplied by RUBBER PRODUCTS, Riga, Latvia. The devulcanisation was based on mechano-chemical processes in which the sulphur cross links in the polymer chain were uncoupled, but its chemical composition was not changed. TRSE consists of $100 \%$ recycled truck tyres which by nature have a relatively high content of natural rubber. TRSE is pre-treated with special oil and FT-wax component. The special oil could reduce the migration of the lighter components of the binder into the rubber thus minimizing the pre-early aging effect. The FT-wax component in TRSE allows a reduction in mixing temperature, without running the risk of insufficient workability and compactability. The TRSE was supplied by STORIMPEX AsphalTec GmbH. Figure 2 shows the percent passing gradation of rubber particles, and Figure 3 shows 
SEM images taken at different magnifications. SEM images depict that RTR produced by ambient grinding (TRN and TRD) have very irregular shapes and rough surface area which are desirable for rubber-bitumen interaction and hence better physical properties (Lee et al. 2008). Generally, the cryogenic grinding rubbers have smooth fractured surfaces with angular corners. However, the SEM images of TRSE show that the pre-treated process has resulted in rougher texture surface in comparison to SEM images found in other references (Shen \& Amirkhanian, 2005, Thives et al., 2013).

Table 1. The properties of base binders used in this study

\begin{tabular}{l|l|l|l}
\hline Ageing states & Index & Binder "S" & Binder "H" \\
\hline Unaged binder & Penetration @ $25^{\circ} \mathrm{C}, 0.1 \mathrm{~mm}$ & 200 & 40 \\
& Softening point ${ }^{\circ} \mathrm{C}$ & 37.0 & 51.4 \\
& Rotational viscosity, Pa.s & & \\
& $@ 135^{\circ} \mathrm{C}$ & 0.192 & 0.474 \\
& $@ 180^{\circ} \mathrm{C}$ & 0.025 & 0.075 \\
& Asphaltenes content & $4.2 \%$ & $15.2 \%$ \\
& $\mid \mathrm{G} * / \sin \delta @ 60^{\circ} \mathrm{C} \& 1.59 \mathrm{~Hz}, \mathrm{kPa}$ & 0.615 & 1.95 \\
\hline RTFOT aged residue & $\mathrm{G} * \mid \sin \delta @ 60^{\circ} \mathrm{C} \& 1.59 \mathrm{~Hz}, \mathrm{kPa}$ & 1.256 & 7.70 \\
\hline RTFOT + PAV aged residue & $\mathrm{G} * \mid \cdot \sin \delta @ 20^{\circ} \mathrm{C} \& 1.59 \mathrm{~Hz}, \mathrm{kPa}$ & 1050 & 10027 \\
\hline
\end{tabular}

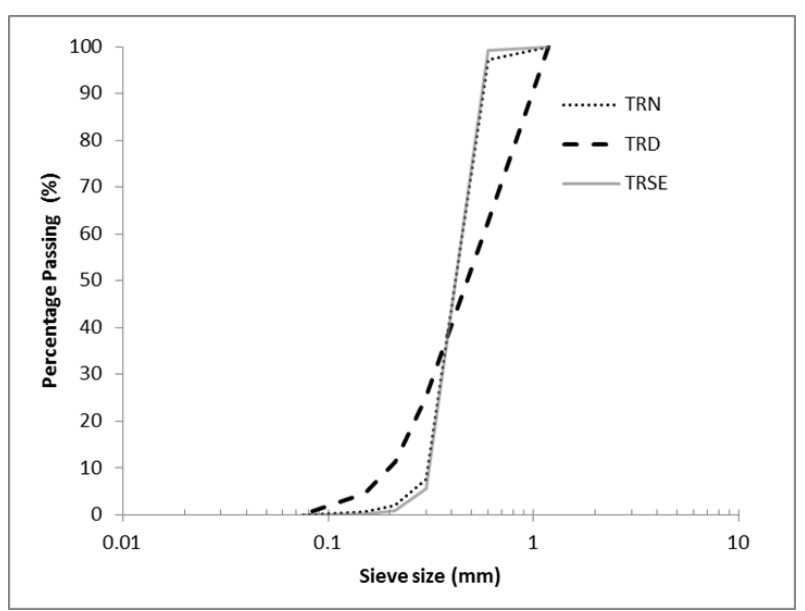

Figure 2. The passing percent gradation of RTRs 

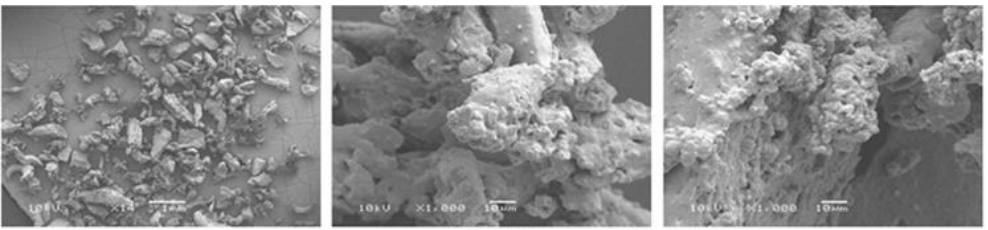

(a) TRN
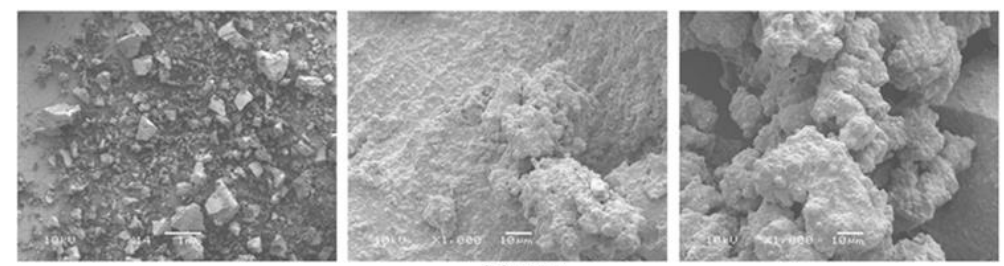

(b) TRD
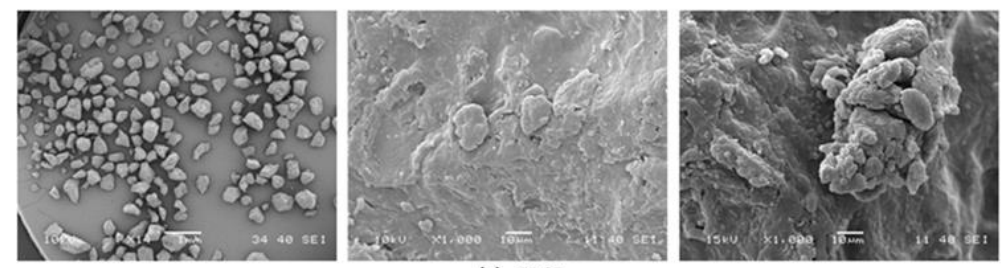

(c) TRSE

Figure 3. SEM images for the different RTRS

\subsection{Manufacturing RTR-MBs}

The rubber percentage mass was kept constant for all RTR-MBs combinations, $18 \%$ by bitumen weight which is equal to $15.25 \%$ of total blend. This concentration was chosen based on previous studies (Celauro et al. 2012, Presti \& Airey 2013, Wang et al. 2012) which showed that increasing the CRM content from $20 \%$ to $25 \%$ has resulted in minor changes on high temperature viscosity and low temperature stiffness. The mixing temperature and time were selected to be $180^{\circ} \mathrm{C}$ and $140 \mathrm{~min}$, respectively, and to match the commonly used specifications ASTM D6114, CalTrans Bitumen Rubber User Guide, SABITA Manuel 19, VicRoads and APRG Report No. 19 and Austroads User Guide and previous literature (Lo Presti et al. 2012, Memon 2011).

All RTR-MBs combinations were produced using the following procedure in order to eliminate any unwanted side effects. About $200 \mathrm{~g}$ of neat bitumen (contained in a tin) was heated at $160^{\circ} \mathrm{C}$ in the oven for $45 \mathrm{~min}$. The fluid test sample was then stirred and $10 \mathrm{~g}$ of bitumen transferred into separate sample containers (Brookfield viscometer cylinders/tubes). The sample containers (tubes) were then placed in a sealed container to protect them against any unwanted oxidation and then left to cool down to room temperature. Each of the sample containers (tubes) was then placed into the preheated 
temperature control unit of the Brookfield viscometer (preheated to the selected mixing temperature of $180^{\circ} \mathrm{C}$ ) and given $15 \mathrm{~min}$ to obtain equilibrium temperature throughout the sample. The designed rubber quantity ( $1.8 \mathrm{~g}$ to achieve the $18 \%$ rubber content by weight of bitumen) was gradually added while manually stirring the blend with a thin spatula. All the rubber was fed into the sample container (cylinder) within $5 \mathrm{~min}$. After that, the preheated DHI was lowered into the blend of bitumen and rubber and rotated at a constant speed of $100 \mathrm{rpm}$. Viscosity was constantly monitored throughout the mixing time. The mixing time was taken as the time from when the impeller started rotating. Once the designed mixing time (140 $\mathrm{min})$ was reached, the sample container was taken out of the temperature control unit and the RTR-MB poured directly into a $10 \mathrm{ml}$ vial. The vial was left to cool down to room temperature before being sealed and stored in a cold store at $5^{\circ} \mathrm{C}$ for future DSR testing. The different RTR-MBs were labelled in such way to give information about the base binder and RTR source. For example, the code of (STRN) means, soft bitumen "S" blended with TRN. Each RTR-MBs blending was reproduced at least twice.

\subsection{Rubber dissolution test}

The following gravimetric procedure was used to determine the RTRs that dissolved into the bitumen (Ghavibazoo and Abdelrahman 2013):

1. Approximately $3 \mathrm{~g}$ of RTR-MB was transferred into an Erlenmeyer flask and the mass of the sample determined to the nearest $1 \mathrm{mg}$.

2. About $100 \mathrm{ml}$ of toluene was then added to the flask with continuous agitation until most lumps disappear and the flask was then place into a steam bath for $30 \mathrm{~min}$.

3. The solution was then strained through a pre-weighed \#200 $(75 \mu \mathrm{m})$ mesh and the retained insoluble rubber particles were washed with extra toluene until the filtrate flow was substantially colourless.

4. The \#200 mesh was then heated in an oven at $110^{\circ} \mathrm{C}$ for $30 \mathrm{~min}$, removed from the oven and placed in a desiccator for $30 \mathrm{~min}$ and the mass determined to the nearest $0.1 \mathrm{mg}$. The drying and weighing were repeated until constant mass is attained.

5. The rubber that did not dissolve into the bitumen (rubber particles $>75 \mu \mathrm{m}$ ) was calculated by taking the difference in mass between the final (containing insoluble rubber particles) and initial (clean) \#200 mesh. The percent of rubber dissolution was then determined based on the initial rubber content.

6. Three replicates were made for each blend. 


\subsection{Rheological investigation by means of Dynamic Shear Rheometer (DSR)}

1. Dynamic Mechanical Analysis (DMA) tests: Dynamic Shear Rheometer (DSR) from Malvern Instruments Ltd, (Kinexus) was used for DMA of RTR-MBs. All RTRMBs samples were tested under the following settings with at least two replicates:

- Frequency sweep $(0.1-10 \mathrm{~Hz})$

- Strain control mode within the LVE (less than 1\%)

- Temperatures $\left(30^{\circ} \mathrm{C}-80^{\circ} \mathrm{C}\right.$ at $10^{\circ} \mathrm{C}$ intervals)

- Plate geometry was $25 \mathrm{~mm}$ diameter parallel plates with $2 \mathrm{~mm}$ gap to minimise the effect of rubber particles on the viscoelastic measurements.

- All tests were conducted on unaged samples.

2. Multiple Stress Creep and Recovery (MSCR) test: Dynamic Shear Rheometer CVO was used for MSCR test. The test consists of applying 1s creep shear stress and recovery for $9 \mathrm{~s}$. At least two replicates were made. The test methodology follows the standard ASTM D 7405, but the difference here was the use of multiple stresses instead of using only two stresses $(0.1 \mathrm{kPa}$ and $3.2 \mathrm{kPa})$ to examine the stress sensitivity of RTR-MBs. The following sequence was used for MSCR test:

- Isothermal temperature of $60^{\circ} \mathrm{C}$

- Seven stress levels were used (100, 400, 1600, 3200, 6400, 12800 and $25600 \mathrm{~Pa}$ ). The sequence was designed so that there were no rest periods between creep and recovery cycles or changes in stress level.

- Applying 10 cycles at each stress level.

- Plate geometry was $25 \mathrm{~mm}$ diameter parallel plates with $2 \mathrm{~mm}$ gap.

- All tests were conducted on unaged samples.

\section{Results and discussion}

\subsection{HTV of RTR-MBs}

The viscosity of binder at high temperatures is important for pumpability and to ensure that the binder can be practically mixed and compacted with aggregate. According to SHRP specifications, the HTV must not be higher than $3000 \mathrm{mPa} . \mathrm{s}$ at $135^{\circ} \mathrm{C}$ (Kennedy et al. 1994). However, RTR-MBs tend to have HTV which exceeds this limit due to the particulate nature of rubber and swelling effect. Therefore, higher mixing and 
compaction temperatures are normally considered in manufacturing RTR-MBs mixtures (Akisetty et al. 2009a, Lee et al. 2008). Figure 4 shows the viscosity progression over time for both base binders " $\mathrm{S}$ " and " $\mathrm{H}$ " interacted with different RTRs at $180^{\circ} \mathrm{C}$. The viscosity values for the base bitumen (binders " $\mathrm{S}$ " and " $\mathrm{H}$ ") at $180^{\circ} \mathrm{C}$ have also been included in the plots at a time of -5 min which corresponds to the $5 \mathrm{~min}$ period required to manually add the rubber particles to the blend. Three parameters corresponding to the maximum swelling, swelling rate (increasing viscosity with time) and maturation time (time to reach maximum viscosity) are quantitatively evaluated from the viscosity progression in Figure 4 and are listed in Table 2. The maximum swelling represents the relative increase in viscosity and is calculated using Eq.1.

$$
\text { The maximum swelling }=\frac{v_{p}-v_{i}}{v_{i}} \quad \text { Eq.1 }
$$

Where $v_{p}$ is the peak viscosity, $v_{i}$ is the initial viscosity which corresponds to $0 \mathrm{~min}$ after manually adding all the rubber particles to the blend, as shown in Figure 4.

The swelling rate is defined here as the rate of viscosity gain with respect to time, and determined by taking the arithmetic average of tangents $(\partial v / \partial \tau)$ of the viscosity progression curves (Figure 4) from the point of adding all the rubber up to the peak viscosity.

Generally, TRD and TRSE have much lower viscosity in comparison to TRN, and that is observed for both binders. RTR-MBs produced using TRD needed very short maturation time in comparison to TRN and TRSE, and then exhibited reduction in viscosity due to the devulcanisation and depolymerisation of the rubber particles. This time was also slightly shorter for RTR-MBs produced using soft binder " $S$ " than those produced using hard bitumen " $H$ ". This is explained as the softer base binder (lower viscosity) with higher aromatic content has a higher rate of penetration (diffusion) into the rubber particles, and thus faster swelling.

The swelling rate of RTR-MBs produced using TRN and TRD are much higher than that of RTR-MBs produced with TRSE. This could be attributed to the difference in grinding process of RTRs and the percentage of natural rubber in RTRs where both TRN and TRD were ambient ground while TRSE was cryogenically ground and consists of $100 \%$ truck tyres.

The difference in maximum swelling between different RTRs on the one hand and the base binder on the other is significant as can be seen in Table 2. However, TRN was not significantly influenced by the base binder. While, the opposite trend was found for TRD and TRSE where there is a significant decrease in maximum swelling with binder " $H$ ". As explained in the literature, the maximum swelling depends mainly on the viscosity and chemical nature of base binders as well as the cross-links density of the rubber (McCrum et al.1997, Treloar 1975). The lower the viscosity, the more readily the bitumen will diffuse into the rubber particles. In addition, the greater the 
cross-links density, the shorter the average length of rubber chains between crosslinks and the lower the maximum swelling.

The initial viscosity $v_{i}$ is mostly governed by the particulate effect of RTRs as an inert filler where the effect of swelling and interaction can be considered minimal. The influence of RTRs on $v_{i}$ is very clear for both base binders. The results clearly show that $v_{i}$ was greatly increased by TRN in comparison to TRD and TRSE. It seems that the pre-treated process for TRD and TRSE led to significant decrease in $v_{i}$. Also, the significant reduction in $v_{i}$ for RTR-MBs produced using TRSE can be attributed to the special oil and FT-wax activation in addition to the grinding method. FT-wax has the ability to liquefy and significantly reduce the blending viscosity beyond its melting point (Jamshidi et al. 2013). Also, research results have indicated that binder modified by cryogenically ground RTR can exhibit lower viscosities than binder modified by ambient ground RTR (Thodesen et al. 2009).

Finally, the viscosity of RTR-MBs blended using bitumen " $H$ " for each RTRs over a range of temperatures is shown in Figure 5. The results show that RTR-MBs produced using TRN yielded the highest viscosities and exceeded the $3000 \mathrm{mPa}$.s SHRP limit, on the opposite side both RTR-MBs produced using TRD and TRSE exhibited lower viscosities and they were within the SHRP limit.

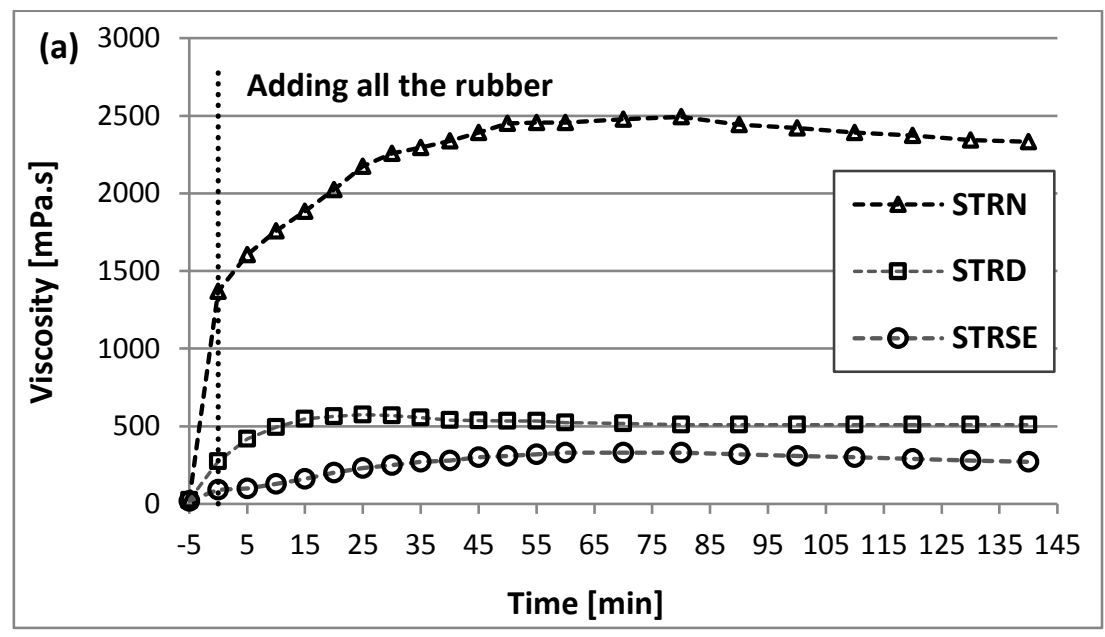


10 EATA 2015

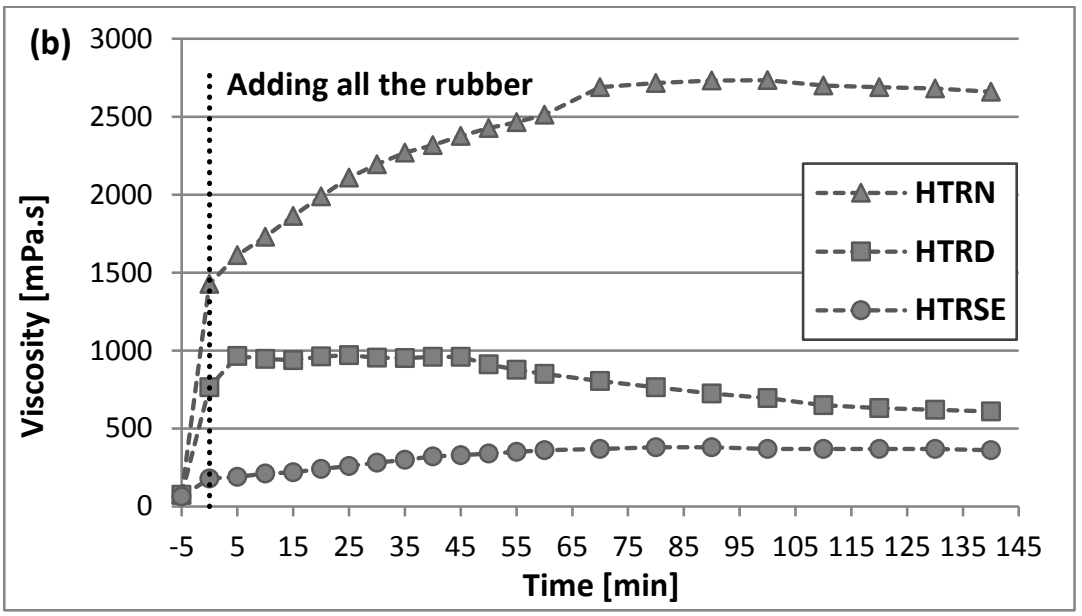

Figure 4. Viscosity progression over time (a) RTR-MBs produced using bitumen " $S$ " and (b) RTR-MBs produced using bitumen " $H$ "

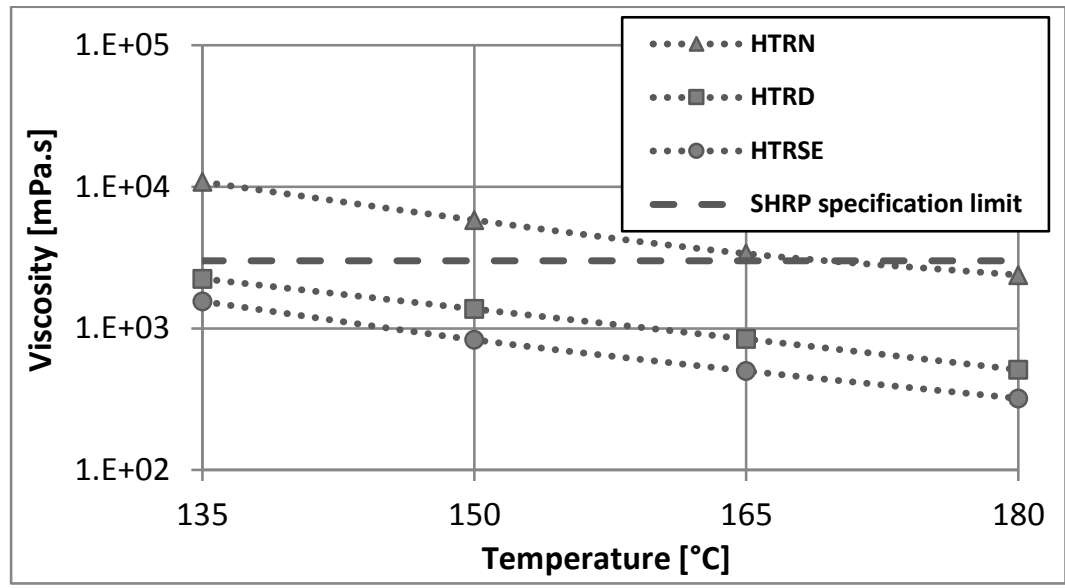

Figure 5. HTV of RTR-MBs produced using bitumen " $H$ "

Table 2. The Interaction parameters

\begin{tabular}{|c|c|c|c|c|c|c|}
\hline Materials & $\begin{array}{l}\text { Swelling } \\
\text { rate } \\
{[\mathrm{mPa} . \mathrm{s} / \mathrm{min}]}\end{array}$ & $\begin{array}{l}\text { Maturation } \\
\text { time } \\
{[\text { min }]}\end{array}$ & $\begin{array}{c}v_{i} \\
{[\mathrm{mPa} . \mathrm{s}]}\end{array}$ & $\begin{array}{c}v_{p} \\
{[\mathrm{mPa} . \mathrm{s}]}\end{array}$ & $\begin{array}{c}\text { Maximum } \\
\text { Swelling } \\
\%\end{array}$ & $\begin{array}{c}\text { Final viscosity } \\
\text { @ 140min } \\
\text { [mPa.s }]\end{array}$ \\
\hline "STRN & 17 & 80 & 1370 & 2492 & 0.82 & 2331 \\
\hline STRD & 12 & 25 & 275 & 575 & 1.09 & 511 \\
\hline STRSE & 4 & 70 & 90 & 330 & 2.66 & 270 \\
\hline HTRN & 16 & 100 & 1426 & 2730 & 0.91 & 2660 \\
\hline HTRD & 8.2 & 25 & 765 & 960 & 0.25 & 610 \\
\hline HTRSE & 2.6 & 90 & 180 & 380 & 1.11 & 360 \\
\hline
\end{tabular}




\subsection{RTRs dissolution}

A gravimetric procedure was used to determine the RTR particles that dissolve into the bitumen. The assumption is that particles less than $75 \mu \mathrm{m}$ can be considered to be dissolved in the bitumen rather than present in the bitumen as solid intrusions.

Increasing solubility of the RTR particles is usually associated with good storage stability with the test being undertaken to identify the final storage stability of the RTR-MBs product and the overall state of the material (Leite et al, 2001). Figure 6 shows the average RTR dissolution results for the different RTR types processed with bitumen " $S$ " and " $H$ ". The error bars represent the maximum and minimum values for the replicates. It can be seen that the RTR-MBs produced using TRSE had the greatest dissolution percent which can possibly be translated into better storage stability. On the other hand, RTR-MBs produced using TRD showed the smallest percent of dissolution percent. This is not expected since the TRD already contains $20 \%$ devulcanised rubber which is easier to dissolve into the base binder. The effect of the base binder on the dissolution percentages is apparent at RTR-MBs produced using TRN with soft bitumen " $\mathrm{S}$ " seems more significant than harder bitumen " $\mathrm{H}$ " at dissolving the rubber.

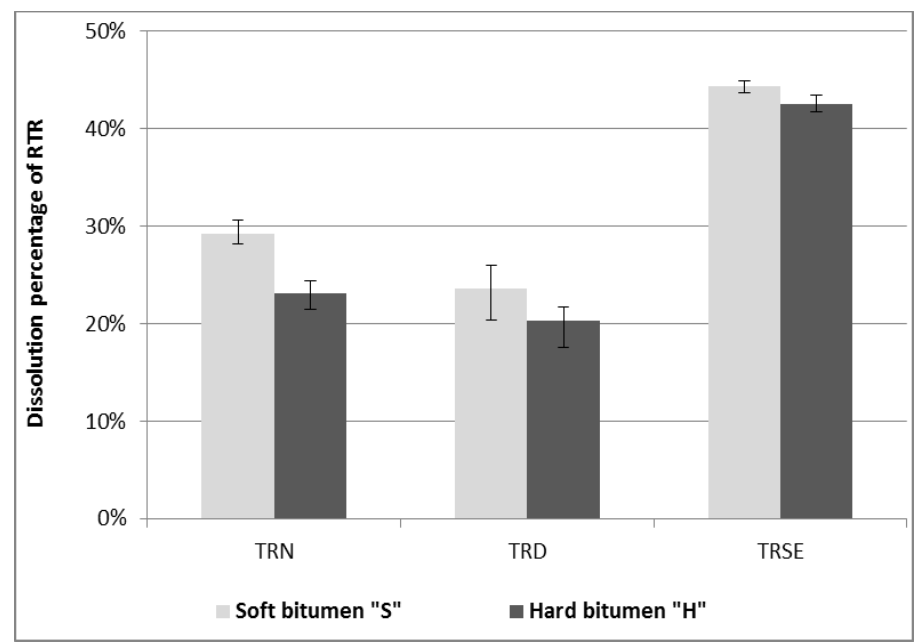

Figure 6. RTRs dissolution percentages

\subsection{Dynamic Mechanical Analysis (DMA)}

The rheology and viscoelastic properties of different RTR-MBs were evaluated under different loading times and temperatures. This has been achieved by means of DMA to define the stress-strain-time-temperature response of the binders. Master curves of complex modulus $\left(\left|\mathrm{G}^{*}\right|\right)$ at a reference temperature of $30^{\circ} \mathrm{C}$ were produced for the RTR-MBs using the Time Temperature Superposition Principle (TTSP). Black 
diagrams can also be used to show the relation between stiffness and viscoelasticity of materials without the need to apply shift factors to the raw data as required for master curves (Airey 2002). Also, the presence of the polymer structure within the RTR-MBs and their thermo-rheological properties can be conveniently distinguished in one plot. Figure 7 shows the master curves for the RTR-MBs produced using different RTRs and two base binders " $\mathrm{S}$ " and " $\mathrm{H}$ ". It is clear from Figure 7 that rubber modification has influenced the properties of the RTR-MBs. The master curves show that rubber modification has resulted in a significant increase in the complex modulus at low frequencies (equivalent to high temperature response) and consequently the RTR-MBs can be expected to have enhanced rutting behaviour. This increased stiffness can be attributed to the dominance of the rubber (polymer) network formation which is stiffer and more elastic than the viscous phase of the base binders (Airey et al. 2002, Navarro et al. 2005). However, the rubber modification is less effective within the base bitumen dominant areas (low temperatures and high frequencies) and the curves tend to come together, apart from the RTR-MBs processed with TRSE and "S" bitumen. The increase in the complex shear modulus $\left(\left|G^{*}\right|\right)$ for the STRSE blend within the base bitumen dominant areas can be due to the effect of FT-wax. The FT-wax forms a crystal lattice structure in the modified binder at temperatures lower than its melting point, and this prevents the movement of molecules in the modified binder, consequently stiffening the modified binder (increasing the viscosity) at low and intermediate temperatures (Jamshidi et al. 2013). However, the FT-wax effect was not as clearly marked in HTRSE as in STRSE. The clarification of the aforementioned behaviour of HTRSE might be due to the inherited higher stiffness of binder " $\mathrm{H}$ " which made the effect of FT-wax less prominent.

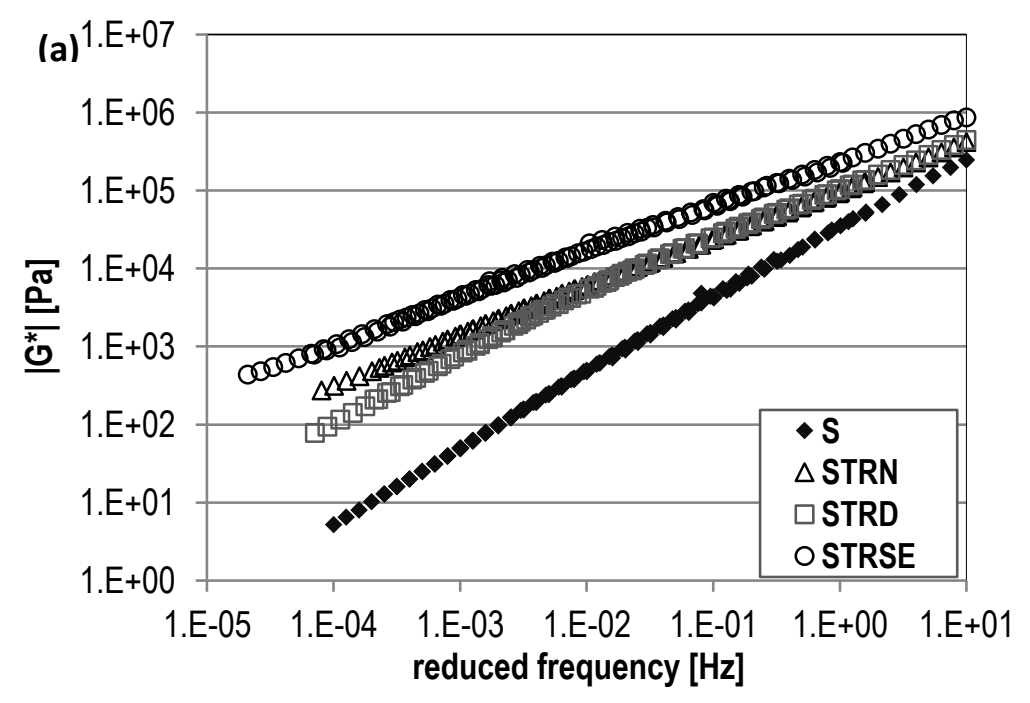




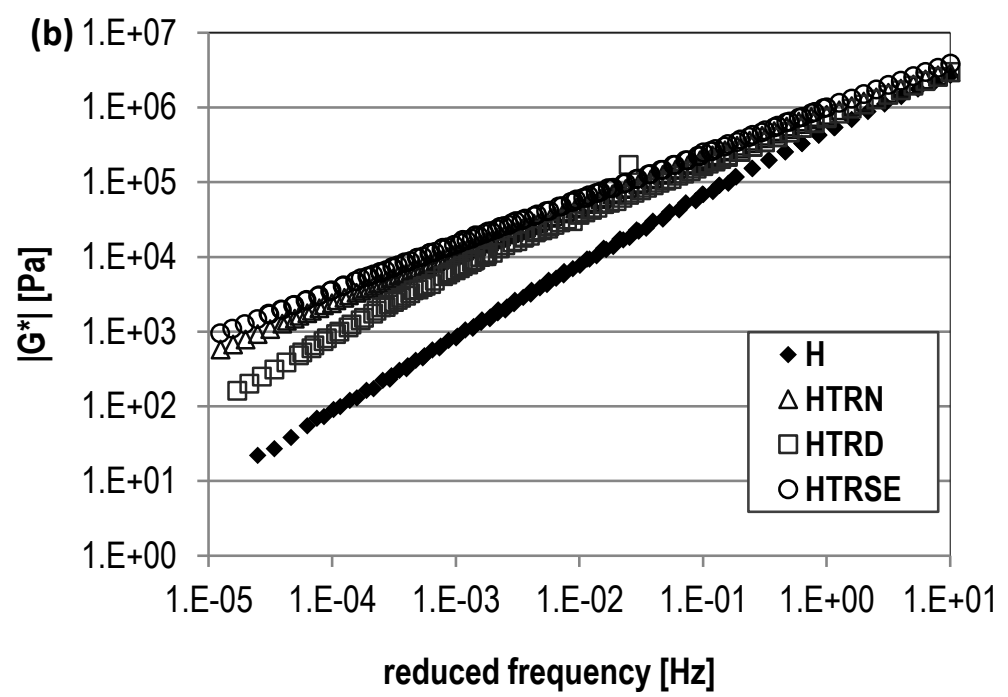

Figure 7. Master curve at $30^{\circ} \mathrm{C}$ reference temperature of $R T R-M B$ s produced using (a) bitumen " $S$ " and (b) bitumen " $H$ "

Figure 8 shows a clear shift for the RTR-MBs to lower phase angles (improved elastic response) compared to their respective base bitumens. The decreased phase angle at higher temperatures and low frequencies can be related to the establishment of a rubber (polymer) rich phase which gains dominance over the almost pure viscous behaviour of the base binders. The complexity and the different patterns of RTR-MB Black curves demonstrate the sensitivity of phase angle measurements to the microstructural modifications and chemical structure that have been imparted by the addition of rubber. The shapes of the RTR-MBs plots in Figure 8 are different from the straight run bitumens. Also each RTR-MB produced using different RTRs has its own distinctive plot. RTR-MBs produced using TRN and " $\mathrm{H}$ " binder formed a typical 3-shape curve, while with "S" binder it formed an uncompleted 3-shape. For RTR-MBs produced using TRSE, the black diagrams tend to be scattered and discontinuous. Providing clear evidence of FT-wax presence and the formation of a lattice structure in the RTR-MBs. The modification level of RTR-MBs produced using TRD was not significant within the polymer rich phase as seen by their black diagrams (higher phase angle measurements in comparison to RTR-MBs produced using TRN and TRSE). 

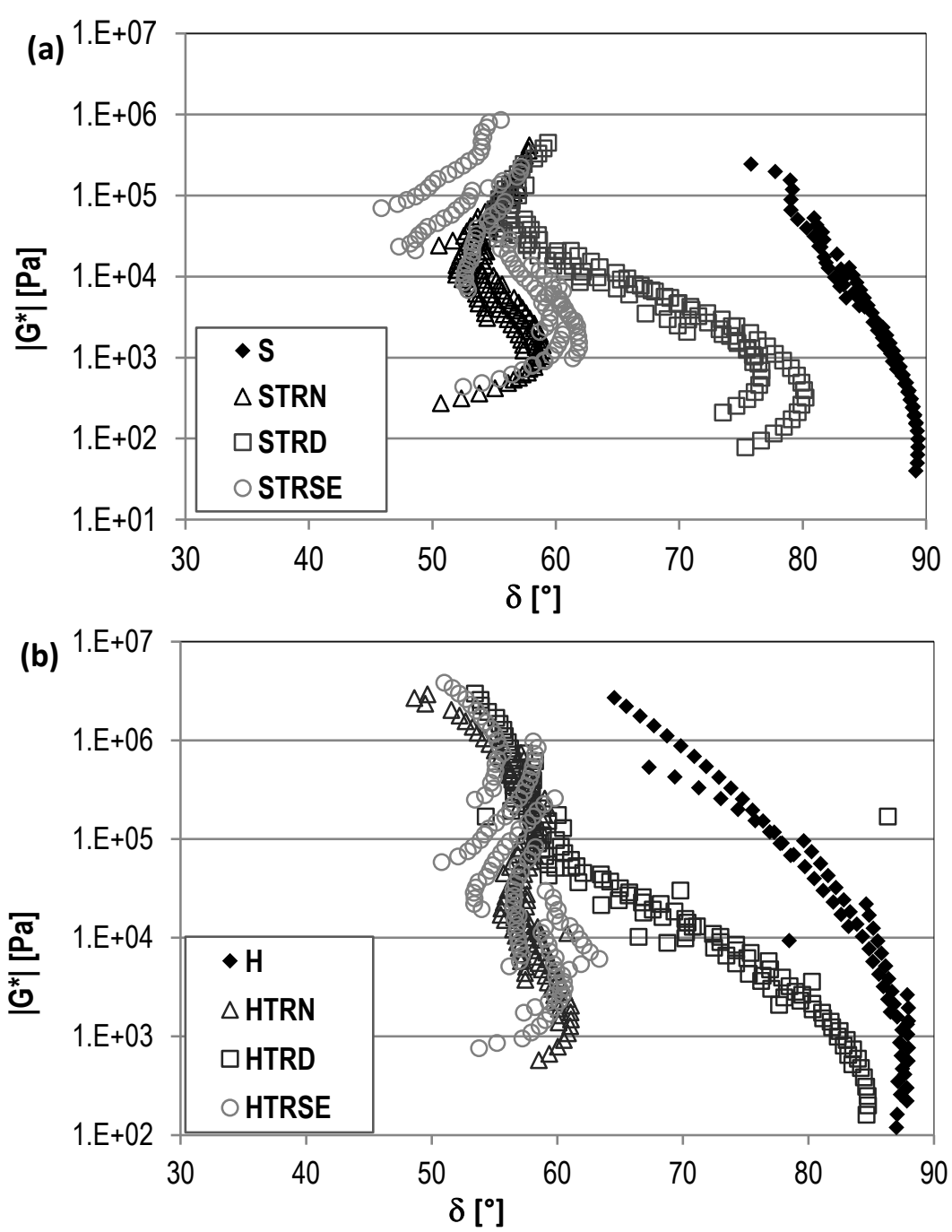

Figure 8. Black diagram of RTR-MBs produced using (a) bitumen " $S$ " and (b) bitumen " $H$ "

\subsection{Rutting resistance properties}

\section{SHRP rutting parameter $\left|G^{*}\right| / \sin \delta$}

The SHRP parameter was derived from the definition of the loss compliance $(\mathrm{J}=\mathrm{sin}$ $\left.\delta /\left|G^{*}\right|\right)$ to measure the contribution of binder to rutting performance (Shenoy 2001). It is therefore necessary to select a binder with reduced ( $\mathrm{J}$ ') for minimising the unrecovered strain $\left(\gamma_{u n r}\right)$ and controlling the rutting. Figure 9 shows the $\left|G^{*}\right| /$ sin $\delta$ values over a range of temperatures between 50 and $80^{\circ} \mathrm{C}$ at a constant frequency of 
$1.59 \mathrm{~Hz}$. It is obvious that the addition of the RTR into both base binders has resulted in a significance improvement to the rutting resistance. Although, the RTR-MBs produced using TRSE had the smallest HTV compared to the other modified binders (see Figure 5), the results in Figure 9 show that TRSE had the largest effects on the enhancement of the SHRP rutting parameter. This highlights the desirable contribution of the FT-wax in TRSE. Reducing the HTV of RTR-MBs by FT-wax is important to ensure that the binder can be pumped and mixed with aggregates. Also, FT-wax can have a significant effect on increasing the rutting resistance of binder due to its crystal lattice structure. TRD shows the smallest effect followed by TRN. The effect of base binder did not change the ranking order of RTR-MBs with respect to their SHRP parameter.
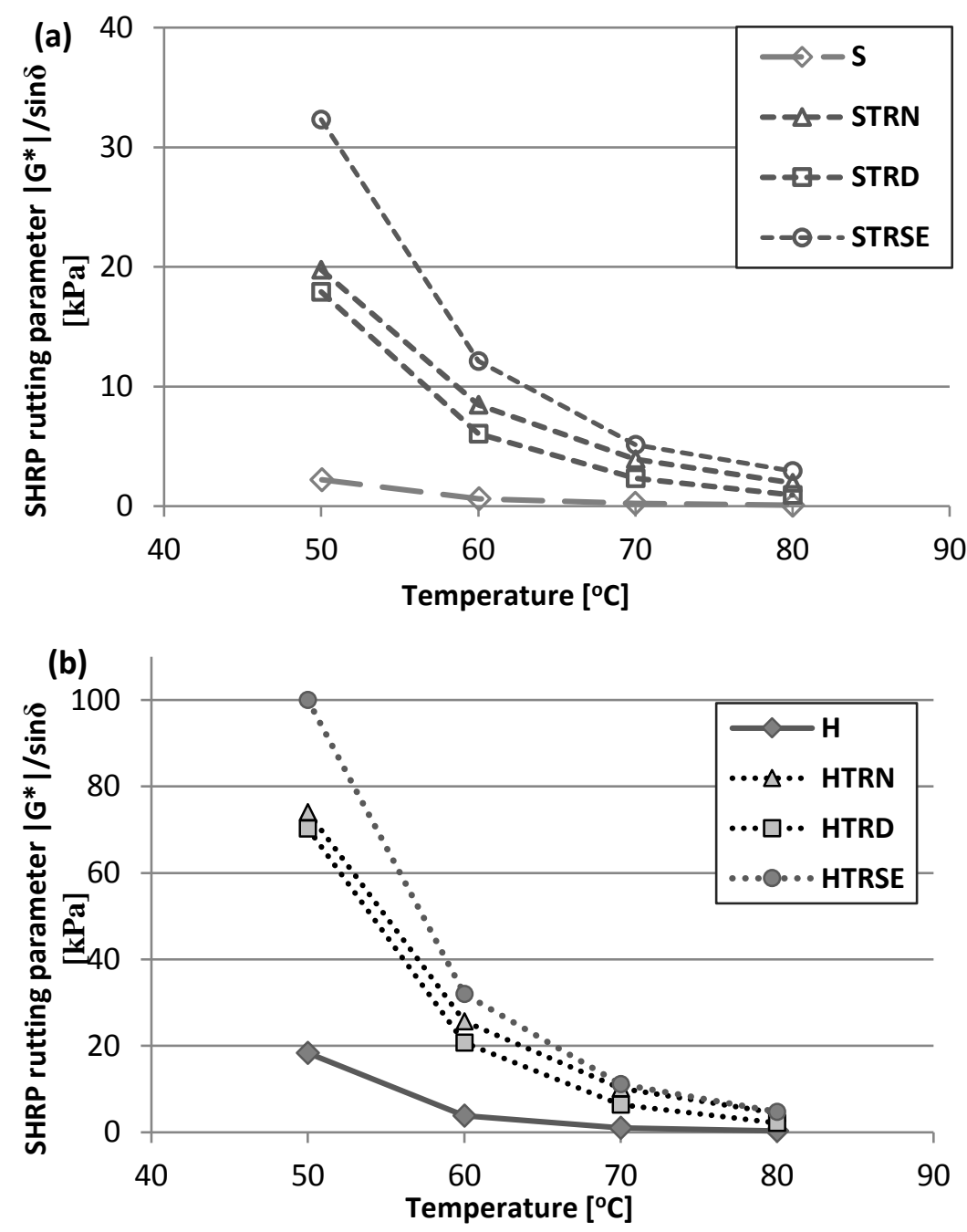
Figure 9. SHRP rutting parameter at $1.59 \mathrm{~Hz}$ of $R T R-M B$ s produced (a) using bitumen " $S$ " and $(b)$ using bitumen " $H$ "

\section{Shenoy rutting parameter $\left|G^{*}\right| /(1-(1 / \sin \delta$ tan $\delta))$}

This parameter was proposed as a refinement to the SHRP parameter (Shenoy 2001). The parameter is more sensitive to phase angle than $\mid G^{*} / / \sin \delta$, therefore it better explains the changes in elastic properties when adding the polymeric modifier. The results of the Shenoy rutting parameter for the different combinations of RTR-MBs in addition to the two run straight binders are presented in Figure 10. The same general trend as for the SHRP parameter is observed here. However, the magnification of the modification effect is much larger with Shenoy compared to the SHRP parameter. Also, the results show that the relative difference between Shenoy parameter for RTRMBs produced using TRD and other two groups was much larger in comparison to the SHRP parameter particularly for the soft base binder. This was due to the relative increase in phase angle measurements (less elastic response) of RTR-MBs produced using TRD compared to other RTR-MBs combinations and that was significantly reflected in the Shenoy parameter.

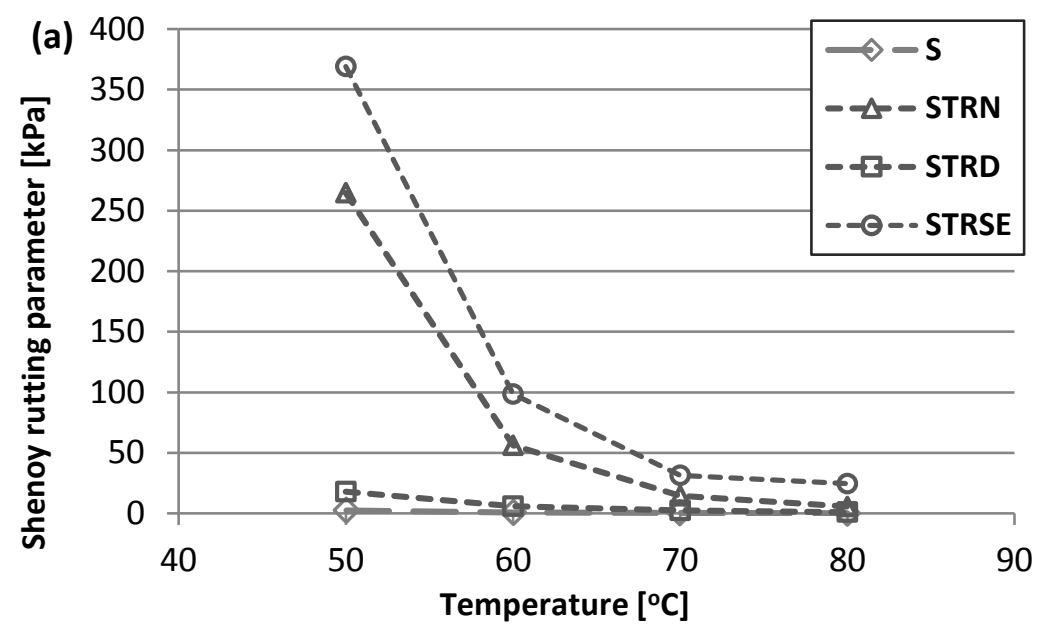




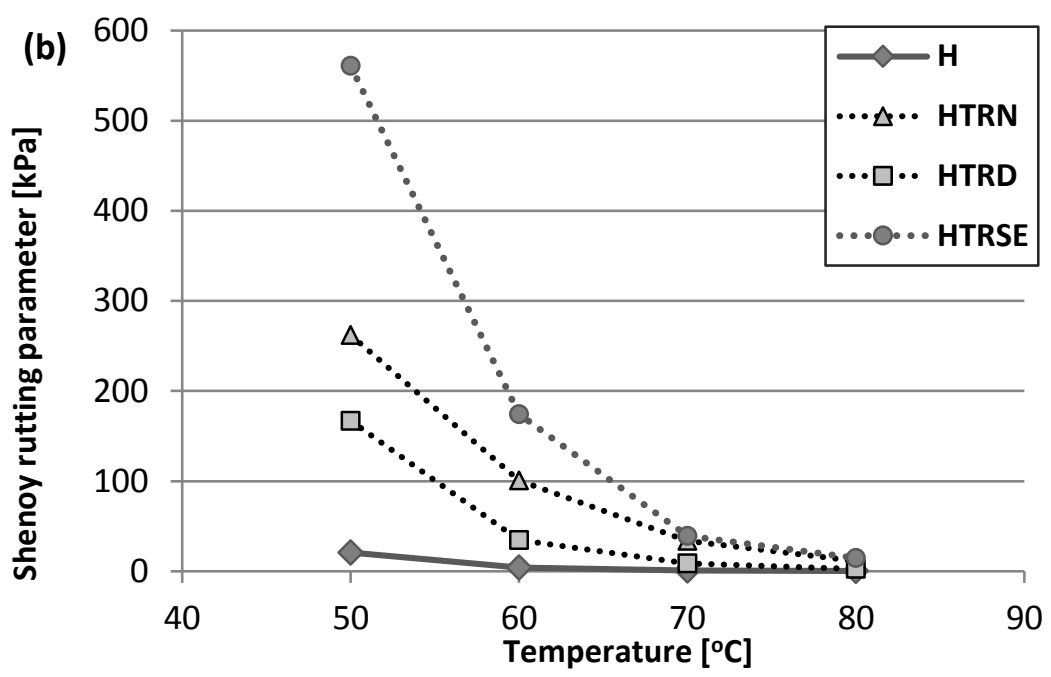

Figure 10. Shenoy rutting parameter at $1.59 \mathrm{~Hz}$ of RTR-MBs produced using (a) bitumen " $S$ " and (b) bitumen " $H$ "

\section{Zero Shear Viscosity ZSV}

Zero shear viscosity is defined as a measure of viscosity under steady state flow conditions when the shear rate approaches zero and it is a physical property of the material that is independent of shear rates and stress. The ZSV concept is based on the fact that the purely dissipative viscous component is solely responsible for the non-recoverable deformation (Airey 2004). ZSV is determined by utilizing cyclic oscillatory tests within the linear viscoelastic regime. The oscillatory data at a test temperature of $60^{\circ} \mathrm{C}$ was selected for $\mathrm{ZSV}$ calculations. The simplified three parameters of the Cross model are used to fit the data and extrapolate the complex viscosity to very low or zero frequency as shown in Figure 11 and demonstrated in Eq.2.

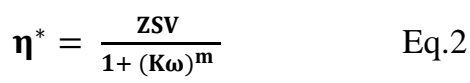

Where $\eta *$ is complex viscosity, ZSV is zero shear viscosity, $\omega$ is frequency $(\mathrm{rad} / \mathrm{s})$, $\mathrm{K}$ and $\mathrm{m}$ are constants. It is clear that ZSV was increased by the addition of RTR which could be translated in improving the rutting resistance of pavement. The different RTR-MBs groups were ranked similarly according to ZSV, SHRP and Shenoy rutting parameters. Also, the nature of modification of different RTRs on ZSV evolution was not affected by the base binder. It can be seen that the behaviour of the straight run bitumens are independent of the applied frequency (Newtonian fluid like behaviour) and the ZSV can be readily identified by the asymptote. Contrarily, the RTR-MBs combinations were sensitive to the frequency and 
exhibited Non-Newtonian behaviour (shear thinning). However, the RTR-MBs produced using TRD showed less sensitivity to the shear rate and a plateau was evident at low frequencies.
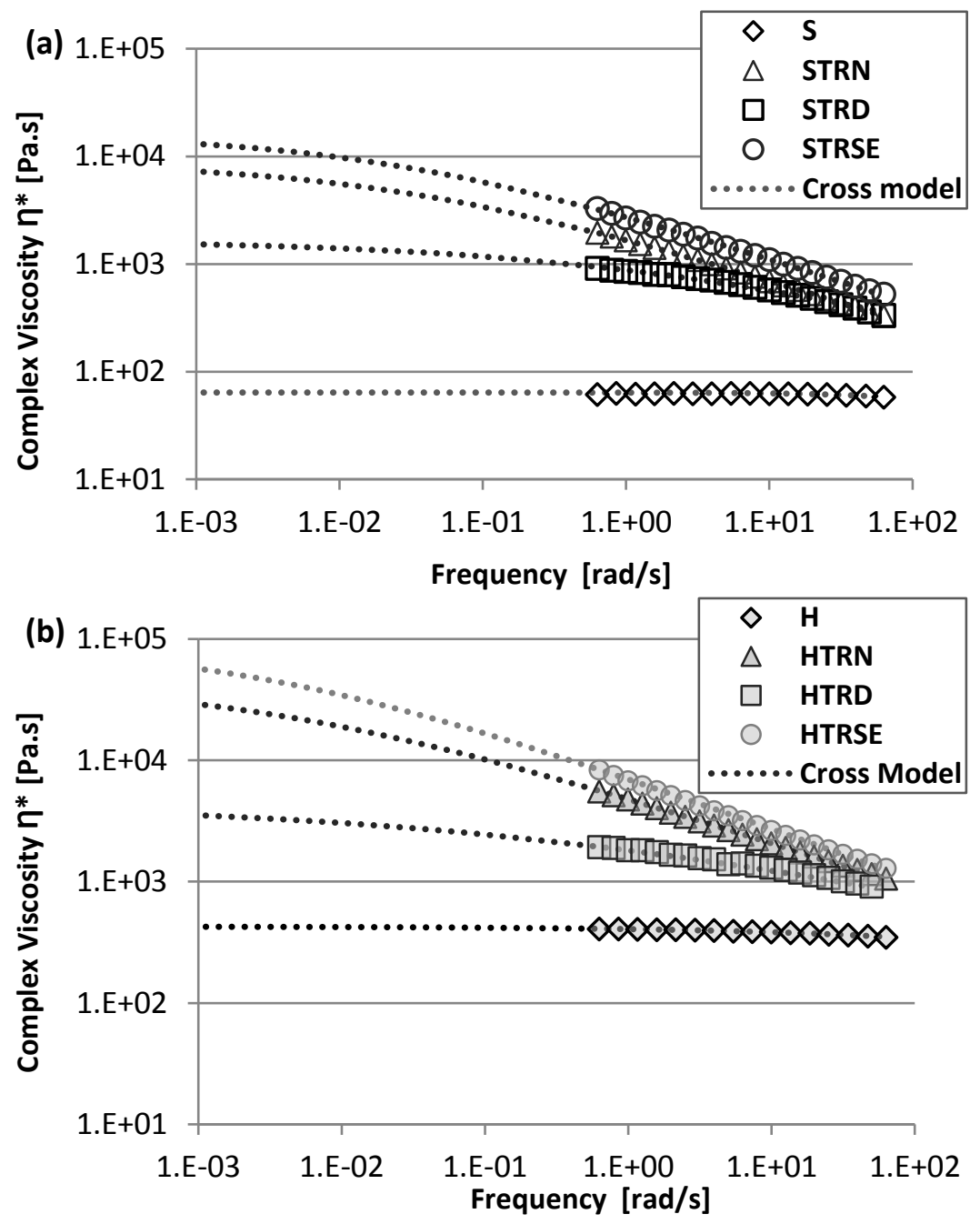

Figure 11. Complex viscosity of RTR-MBs produced using (a) bitumen " $S$ " and (b) bitumen " $H$ "

\section{Multiple Stress Creep and Recovery (MSCR)}

The MSCR test which is based on binder creep and recovery characterization was firstly developed by the NCHRP 9-10 research program (Bahia et al. 2001). The validity of the test to characterise the binders at high-temperature has been ascertained 
by many researchers (D'Angelo et al. 2006, Tabatabaee and Tabatabaee 2010, Wasage et al. 2011, Gibson, M. et al. 2012, Zoorob et al. 2012) . Non-recoverable creep compliance (Jnr) has been recommended as an alternative to the current SHRP parameter $\mid \mathrm{G}^{*} / \mathrm{sin} \delta$ when assessing the permanent deformation performance of different bitumens (D'Angelo et al., 2007). Jnr has the ability to predict the improvement that is imparted by modification, and it is also more sensitive to the stress dependence of modified binders making it suitable for specification purposes for both neat and modified bitumen (D'Angelo 2009, Tabatabaee and Tabatabaee 2010). Also, measuring the Jnr of binders at high stresses and outside the linear viscoelastic region is conceivably more appropriate when considering the rutting behaviour of asphalt mixtures as the strains in binder films on aggregate surfaces can be several hundred times greater than the overall average strain of the mixture. Figure 12 shows the results of Jnr (average value for the 10 creep and recovery cycles) over a wide range of stresses between $0.1 \mathrm{kPa}$ and $25.6 \mathrm{kPa}$ at a test temperature of $60^{\circ} \mathrm{C}$. The addition of rubber has generally resulted in a decrease of the Jnr values of the RTR-MBs groups compared to the base binders. Also, the base binders were tested at lower temperatures than $60^{\circ} \mathrm{C}$ (the soft " $\mathrm{S}$ " at $52^{\circ} \mathrm{C}$ and the hard " $\mathrm{H}$ " at $58^{\circ} \mathrm{C}$ ) because they tended to fail before reaching the highest stress level. Even though, the " $\mathrm{S}$ " was tested at $52^{\circ} \mathrm{C}$ it was damaged at $12.8 \mathrm{kPa}$. The results clearly highlight the significance of stress dependency in RTR-MBs and all the modified binders exhibited shear thinning (increasing Jnr with the applied shear stress). However, the extent varied based on the base binder and the type of RTRs with stress dependency over all stress levels being more apparent in RTR-MBs processed using the soft bitumen " $S$ " and TRSE. It can be seen that STRSE exhibited the most stress sensitivity and changeg from being the one of the best rut resistant binder among the other modified binders at $0.1 \mathrm{kPa}$ stress level to one of the worst at 12.8 and $25.6 \mathrm{kPa}$ stress levels. This could be related to the nature of the lattice structure of FT-wax and the rubber network in STRSE where they form a stiff network at low stresses (within the linear viscoelastic range) but under high stress levels this network may not be strong enough to sustain 
higher strains and act as a single phase in a very soft medium. On the other hand, the HTRN was the most non-compliant binder as indicated by its low Jnr values.
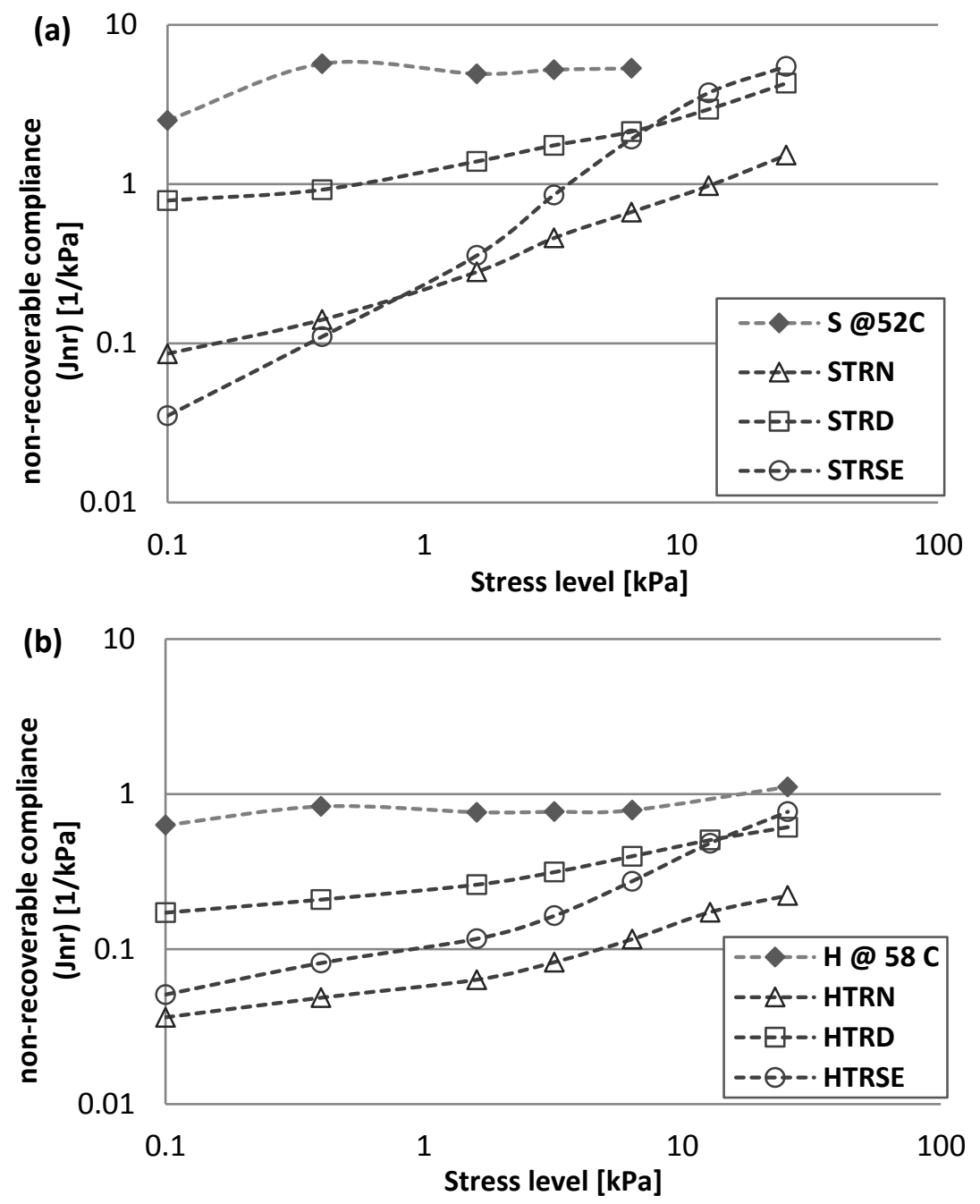

Figure 12. $J_{n r}$ of $R T R-M B$ s produced using (a) bitumen " $S$ " and (b) bitumen " $H$ "

\section{Correlation between the different rutting parameters}

A simple linear regression analysis is applied here between the different rutting parameters in order to find how these parameters are associated with one another. The results in Figure 13a to $\mathrm{c}$ indicated that a reasonable correlation (with $\mathrm{R} 2=0.72$ to 0.85 ) exists between the rutting parameters obtained from the dynamic oscillatory test. However, a lower correlation was found between SHRP rutting parameter and 
Jnr obtained from the MSCR test. Also, the poorest correlation (R2=0.47) was evident in Figure 13e when correlating the Jnr at the highest stress level (25.6 kPa) with the SHRP rutting parameter. This is not surprising as there are many factors associated with the two tests are different. For example, the degree of stress sensitivity, delayed elasticity, relaxation times and nonlinearity all can play a significant role in having different response for materials tested under dynamic oscillatory and creep and recovery conditions.

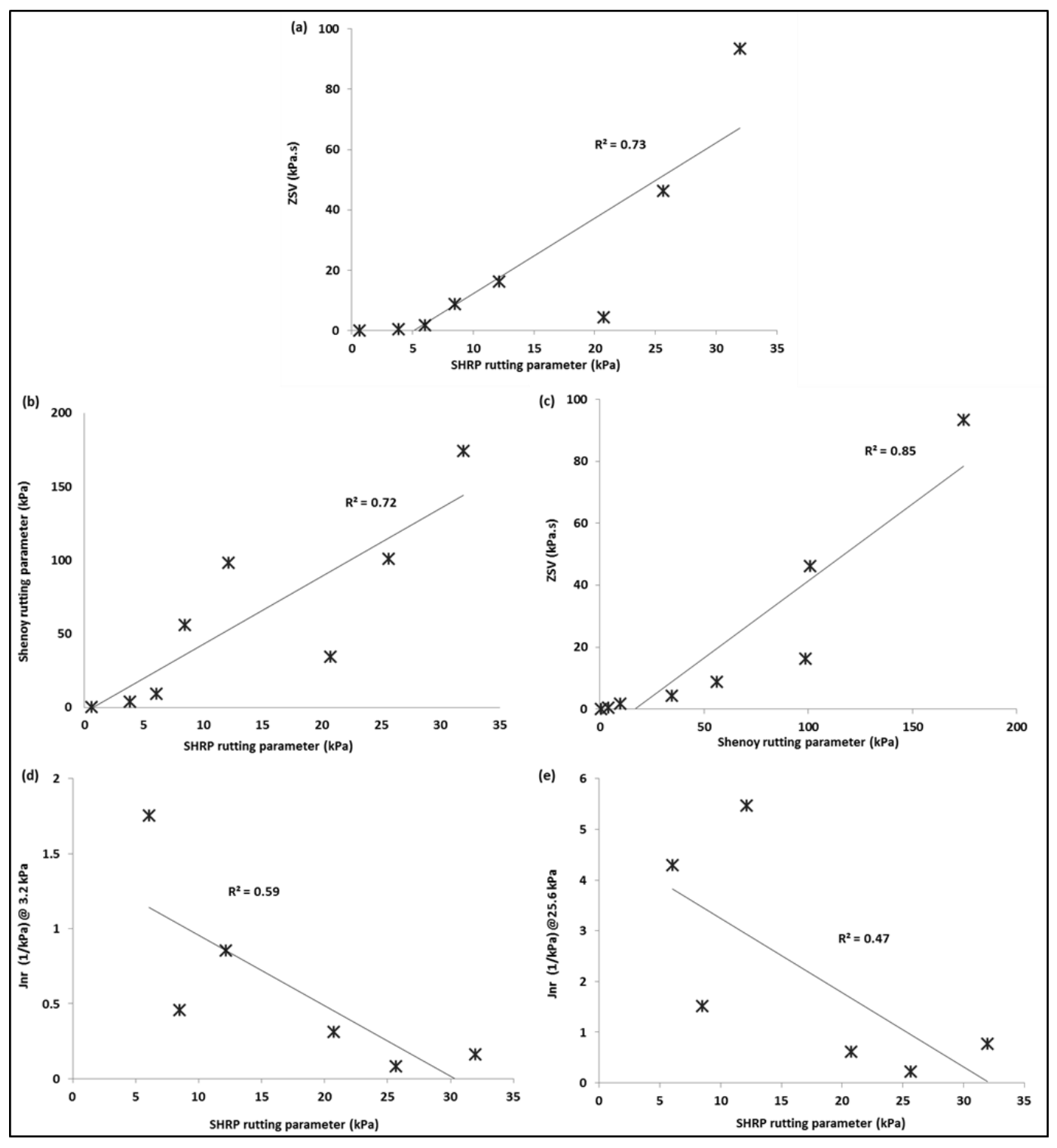


Figure 13. Correlation between different rutting parameters (a) SHRP vs ZSV, (b) SHRP vs Shenoy, (c) Shenoy vs ZSV, (d) SHRP vs Jnr @ $3.2 \mathrm{kPa}$ stress level and (e) SHRPvsJnr@25.6kPa stress level

\subsection{Comparison between HTRSE and SBS modified bitumens}

In this part of the study the HTRSE was compared with two SBS polymer modified bitumens. The first SBS modified bitumen labelled as (SBS-5\%A) was produced in the lab by mixing $5 \%$ of SBS with base bitumen having a penetration of $48 \mathrm{dmm}$. The second SBS modified bitumen labelled as (SBS-3\%B) was also produced in the lab by mixing $3 \%$ of SBS (different SBS) with base bitumen has a penetration of $46 \mathrm{dmm}$. The basis of the comparison was made using the HTV, master curve, black diagram and rutting parameters. In terms of the HTV, Figure 14 showed that HTV at $135^{\circ} \mathrm{C}$ of the HTRSE was significantly lower than the SBS-5\%A and comparable to the SBS$3 \% \mathrm{~B}$ which is desirable for good workability and pumpability. The master curves and SHRP rutting parameter in Figures 15 and 17 proved that the HTRSE is much stiffer at higher in-service temperatures than both SBS modified bitumens and that is preferred for good rutting resistance. However, the high value of $\left|G^{*}\right|$ for the HTRSE at intermediate temperatures may not be beneficial in terms of fatigue resistance (Bahia and Davies, 1994). The black diagram in Figure 16 showed that the elastic response of the HTRSE is better than the SBS-5\%A over all the range of temperatures and frequencies. On the contrary, the black diagram also revealed that the SBS-3\%B was more elastic than the HTRSE at higher temperatures and low frequencies range which demonstrated that SBS-3\%B has an enhanced polymer network within the modified bitumen.

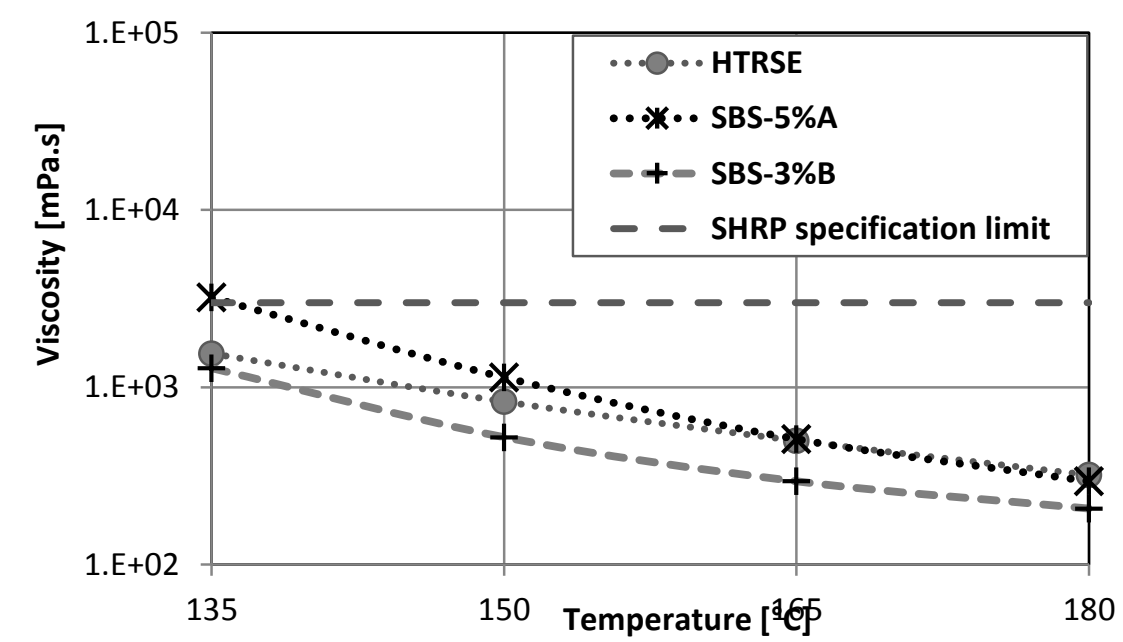

Figure 14. Comparison between HTRSE and SBS modified bitumens - rotational viscosity. 


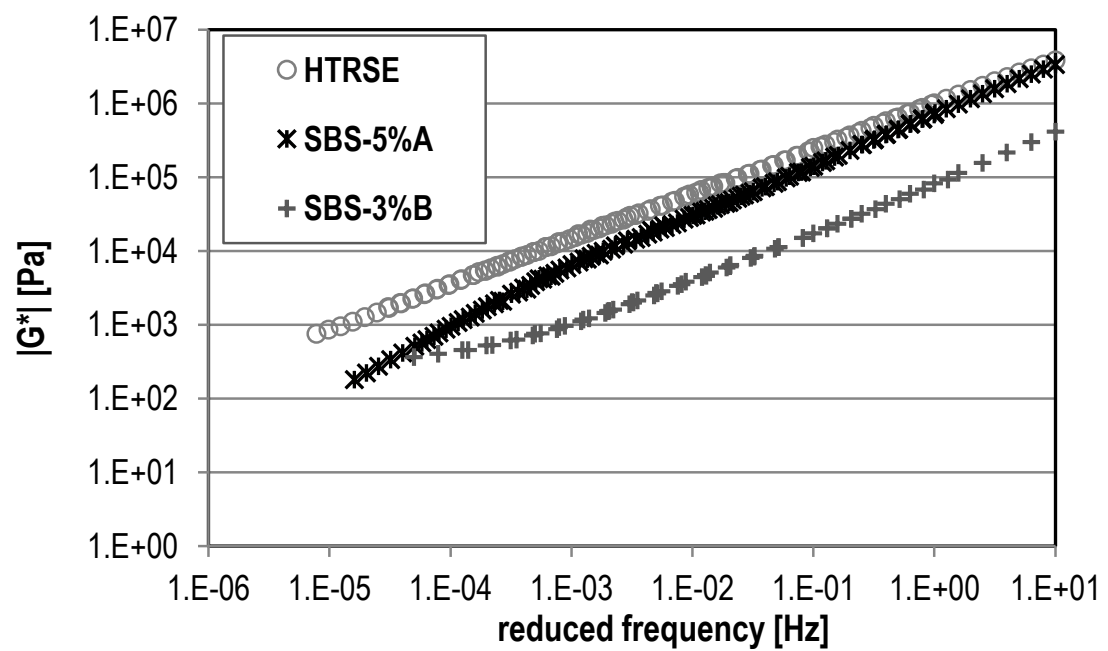

Figure 15 Comparison between HTRSE and SBS modified bitumen- master curves.

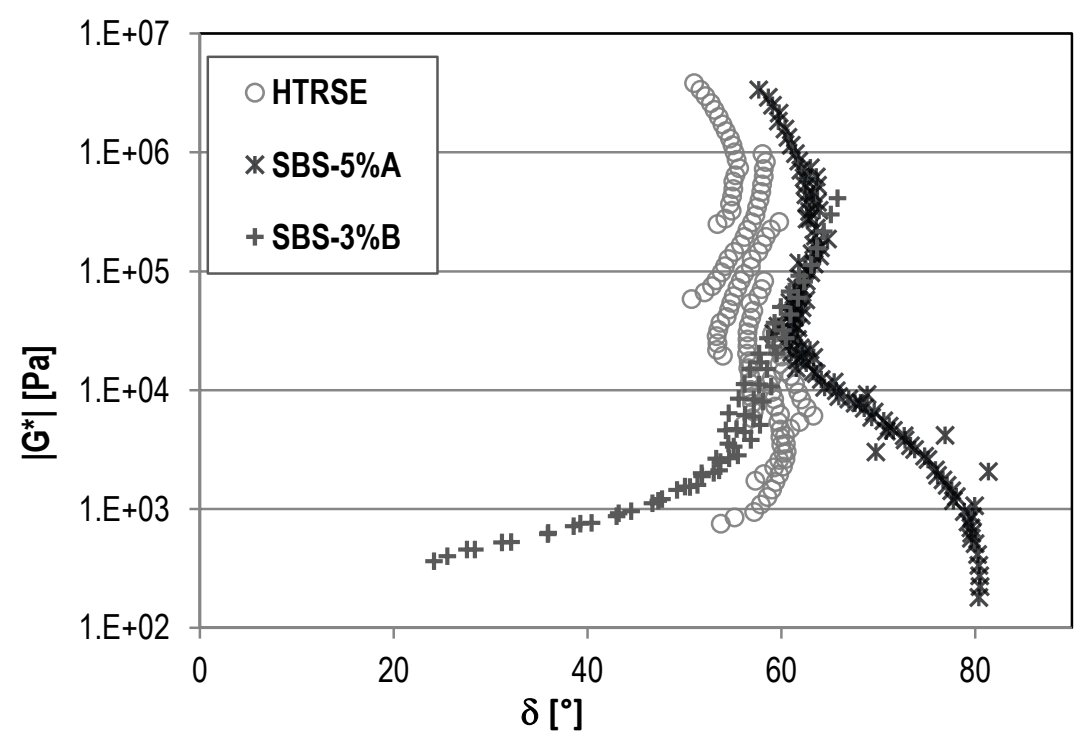

Figure 16. Comparison between HTRSE and SBS modified bitumen- black diagram 


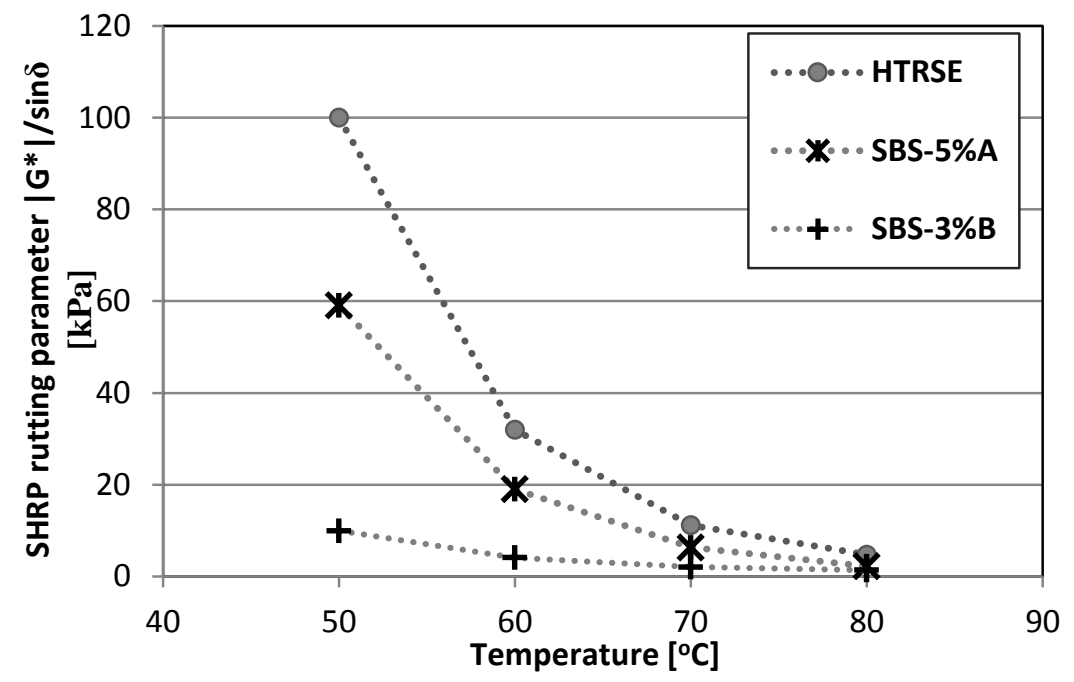

Figure 17. Comparison between HTRSE and SBS modified bitumen-SHRP rutting parameter

\section{Conclusions}

Two pre-treated RTRs and one straight ambient RTR each composed as two mixtures with respectively two binders " $S$ " and "H" were used in this study. The first RTR technology was pre-treated with special oil and Fischer-Tropsch wax (Sasobit ${ }^{\circledR}$ ), the second was partly devulcanised recycled rubber and the third one was a straight ambient ground RTR. The rubber percentage mass was kept constant for all RTRMBs combinations, $18 \%$ by bitumen weight which is equal to $15.25 \%$ of total blend. In general, the addition of RTRs into bitumen can significantly enhance the high temperature performance of binders indicating better resistance to permanent deformation.

Using pre-treated RTRs can significantly reduce the HTV which is important for better handling, wetting the aggregate and to reduce mixing and compaction temperatures. Opposite to this, the straight RTR showed excessively high HTV and exceeded the $3000 \mathrm{mPa}$.s SHRP limit. The results of this study showed that using FTwax activation in rubberized bitumen technology is a promising combination, since it can produce materials with enhanced rutting characteristics, improved storage stability and at the same time have a reasonable HTV. Therefore, it is a preferred option over SBS modification because it is environmental-friendly and cost-effective option. It seems also that the pre-treated process of TRSE has resulted in rougher 
texture surface as depicted by the SEM images which can lead to better rubberbitumen interaction and compatibility.

The materials are ranked differently when the comparison is made between rutting parameters obtained from the dynamic oscillatory test (small strains within LVE range) and the Jnr obtained from the creep and recovery test at very high stress levels. This gives rise to the importance of the realistic strain ranges that actually would take place within binder films in asphalt pavements, and thus selecting the appropriate test method and parameter. However, further asphalt mixture tests by using identical aggregate type and gradation will confirm the appropriate rutting parameter.

\section{Acknowledgements}

The principal author would like to acknowledge the support of the Ministry of Higher Education and Scientific Research of Iraq and the Iraqi Cultural Attaché in London for the PhD scholarship.

\section{Bibliography}

Abdelrahman, M. (2006). "Controlling performance of crumb rubber-modified binders through addition of polymer modifiers." Transportation Research Record: Journal of the Transportation Research Board 1962(1): 64-70.

Airey, G., T. Singleton and A. Collop (2002). "Properties of polymer modified bitumen after rubber-bitumen interaction." Journal of materials in civil engineering 14(4): 344-354.

Airey, G. D. (2002). "Use of black diagrams to identify inconsistencies in rheological data." Road Materials and Pavement Design 3(4): 403-424.

Airey, G. D. (2004). "Fundamental binder and practical mixture evaluation of polymer modified bituminous materials." International Journal of Pavement Engineering 5(3): 137-151.

Akisetty, C., F. Xiao, T. Gandhi and S. Amirkhanian (2011). "Estimating correlations between rheological and engineering properties of rubberized asphalt concrete mixtures containing warm mix asphalt additive." Construction and Building Materials 25(2): 950-956.

Akisetty, C. K., S.-J. Lee and S. N. Amirkhanian (2009). "Effects of compaction temperature on volumetric properties of rubberized mixes containing warm-mix additives." Journal of Materials in Civil Engineering 21(8): 409-415.

Akisetty, C. K., S.-J. Lee and S. N. Amirkhanian (2009). "High temperature properties of rubberized binders containing warm asphalt additives." Construction and Building Materials 23(1): 565-573. 
Attia, M. and M. Abdelrahman (2009). "Enhancing the performance of crumb rubber-modified binders through varying the interaction conditions." International Journal of Pavement Engineering 10(6): 423-434.

Bahia, Hussain U., and Robert Davies. "Effect of crumb rubber modifiers (CRM) on performance related properties of asphalt binders." Asphalt paving technology 63 (1994): 414-414.

Bahia, H. U., D. Hanson, M. Zeng, H. Zhai, M. Khatri and R. Anderson (2001). Characterization of modified asphalt binders in superpave mix design.

Billiter, T., R. Davison, C. Glover and J. Bullin (1997). "Production of asphalt-rubber binders by high-cure conditions." Transportation Research Record: Journal of the Transportation Research Board 1586(1): 50-56.

Billiter, T. C., J. S. Chun, R. R. Davison, C. J. Glover and J. A. Bullin (1997). "Investigation of the curing variables of asphalt-rubber binder." Petroleum science and technology 15(5-6): 445-469.

Celauro, B., C. Celauro, D. Lo Presti and A. Bevilacqua (2012). "Definition of a laboratory optimization protocol for road bitumen improved with recycled tire rubber." Construction and Building Materials 37: 562-572.

D'Angelo, J., R. Dongre and G. Reinke (2006). Evaluation of repeated creep and recovery test method as an alternative to SHRP+ requirements for polymer modified asphalt binders. Fifty-First Annual Conference of the Canadian Technical Asphalt Association (CTAA).

D'Angelo, J., R. Kluttz, R. N. Dongre, K. Stephens and L. Zanzotto (2007). "Revision of the Superpave High Temperature Binder Specification: The Multiple Stress Creep Recovery Test (With Discussion)." Journal of the Association of Asphalt Paving Technologists 76.

D'Angelo, J. A. (2009). "The relationship of the MSCR test to rutting." Road Materials and Pavement Design 10(sup1): 61-80.

Dong, R., J. Li and S. Wang (2011). "Laboratory Evaluation of Pre-Devulcanized Crumb Rubber-Modified Asphalt as a Binder in Hot-Mix Asphalt." Journal of Materials in Civil Engineering 23(8): 1138-1144.

Ghavibazoo, A. and M. Abdelrahman (2013). "Composition analysis of crumb rubber during interaction with asphalt and effect on properties of binder." International Journal of Pavement Engineering 14(5): 517-530.

Glover, C. J., R. R. Davison, J. A. Bullin, C. K. Estakhri, S. A. Williamson, T. C. Billiter, J. F. Chipps, J. S. Chun, P. Juristyarini and S. E. Leicht (2000). A Comprehensive Laboratory and Field Study of High-Cure Crumb-Rubber Modified Asphalt Materials.

Jamshidi, A., M. O. Hamzah and Z. You (2013). "Performance of Warm Mix Asphalt containing Sasobit ${ }^{\circledR}:$ State-of-the-art." Construction and Building Materials 38: 530-553.

Kennedy, T. W., G. A. Huber, E. T. Harrigan, R. J. Cominsky, C. S. Hughes, H. Von Quintus and J. S. Moulthrop (1994). Superior performing asphalt pavements (Superpave): The product of the SHRP asphalt research program, Strategic Highway Research Program, National Research Council. 
Lee, S.-J., C. K. Akisetty and S. N. Amirkhanian (2008). "The effect of crumb rubber modifier (CRM) on the performance properties of rubberized binders in HMA pavements." Construction and Building Materials 22(7): 1368-1376.

Lee, S.-J., S. N. Amirkhanian and S.-Z. Kwon (2008). "The effects of compaction temperature on CRM mixtures made with the SGC and the Marshall compactor." Construction and Building Materials 22(6): 1122-1128.

Leite, L. F. M., R. S. Constantino and A. Vivoni (2001). "Rheological studies of asphalt with ground tire rubber." Road Materials and Pavement Design 2(2): 125-139.

Liang, Z.-Z. (1999). Bituminous compositions prepared with process treated vulcanized rubbers, Google Patents.

Liang, Z.-z. and R. T. Woodhams (1998). Treatment of rubber to form bituminous compositions, Google Patents.

Lo Presti, D., C. Fecarotti, A. T. Clare and G. Airey (2014). "Toward more realistic viscosity measurements of tyre rubber-bitumen blends." Construction and Building Materials.

Lo Presti, D., G. Airey and P. Partal (2012). "Manufacturing terminal and field bitumen-tyre rubber blends: the importance of processing conditions." Procedia-Social and Behavioral Sciences 53: 485-494.

McCrum, N. G., C. Buckley and C. B. Bucknall (1997). Principles of polymer engineering, Oxford University Press.

Memon, N. (2011). "Characterisation of conventional and chemically dispersed crumb rubber modified bitumen and mixtures." University of Nottingham. Nottingham, UK: sn PhD thesis.

Navarro, F., P. Partal, F. Martinez-Boza and C. Gallegos (2005). "Influence of crumb rubber concentration on the rheological behavior of a crumb rubber modified bitumen." Energy \& fuels 19(5): 1984-1990.

Nelson Gibson, X. Q., Aroon Shenoy, Ghazi Al-Khateeb,, A. A. M. Emin Kutay, Kevin Stuart, Jack Youtcheff, and and T. Harman (2012). Performance Testing for Superpave and Structural Validation.

Presti, D. L. and G. Airey (2013). "Tyre rubber-modified bitumens development: the effect of varying processing conditions."

Rodríguez-Alloza, A. M., J. Gallego and I. Pérez (2013). "Study of the effect of four warm mix asphalt additives on bitumen modified with $15 \%$ crumb rubber." Construction and Building Materials 43: 300-308.

Shen, J. and S. Amirkhanian (2005). "The influence of crumb rubber modifier (CRM) microstructures on the high temperature properties of CRM binders." The International Journal of Pavement Engineering 6(4): 265-271.

Shenoy, A. (2001). "Refinement of the Superpave specification parameter for performance grading of asphalt." Journal of transportation engineering 127(5): 357-362. 
Tabatabaee, N. and H. A. Tabatabaee (2010). "Multiple Stress Creep and Recovery and Time Sweep Fatigue Tests." Transportation Research Record: Journal of the Transportation Research Board 2180(1): 67-74.

Thives, L. P., J. C. Pais, P. A. Pereira, G. Trichês and S. R. Amorim (2013). "Assessment of the digestion time of asphalt rubber binder based on microscopy analysis." Construction and Building Materials 47: 431-440.

Thodesen, C., K. Shatanawi and S. Amirkhanian (2009). "Effect of crumb rubber characteristics on crumb rubber modified (CRM) binder viscosity." Construction and Building Materials 23(1): 295-303.

Treloar, L. R. G. (1975). The physics of rubber elasticity, Oxford University Press.

Wang, H., Z. You, J. Mills-Beale and P. Hao (2012). "Laboratory evaluation on high temperature viscosity and low temperature stiffness of asphalt binder with high percent scrap tire rubber." Construction and Building Materials 26(1): 583-590.

Wasage, T., J. Stastna and L. Zanzotto (2011). "Rheological analysis of multi-stress creep recovery (MSCR) test." International Journal of Pavement Engineering 12(6): 561-568.

Xiao-qing, Z., L. Can-hui and L. Mei (2009). "Rheological Property of Bitumen Modified by the Mixture of the Mechanochemically Devulcanized Tire Rubber Powder and SBS." Journal of Materials in Civil Engineering 21(11): 699-705.

Zanzotto, L. and G. J. Kennepohl (1996). "Development of rubber and asphalt binders by depolymerization and devulcanization of scrap tires in asphalt." Transportation Research Record: Journal of the Transportation Research Board 1530(1): 51-58.

Zoorob, S., J. Castro-Gomes, L. Pereira Oliveira and J. O’Connell (2012). "Investigating the multiple stress creep recovery bitumen characterisation test." Construction and Building Materials 30: 734-745. 